\title{
Double-clip counter-traction using a rubber band is a useful and adaptive tool for colonic endoscopic submucosal dissection
}
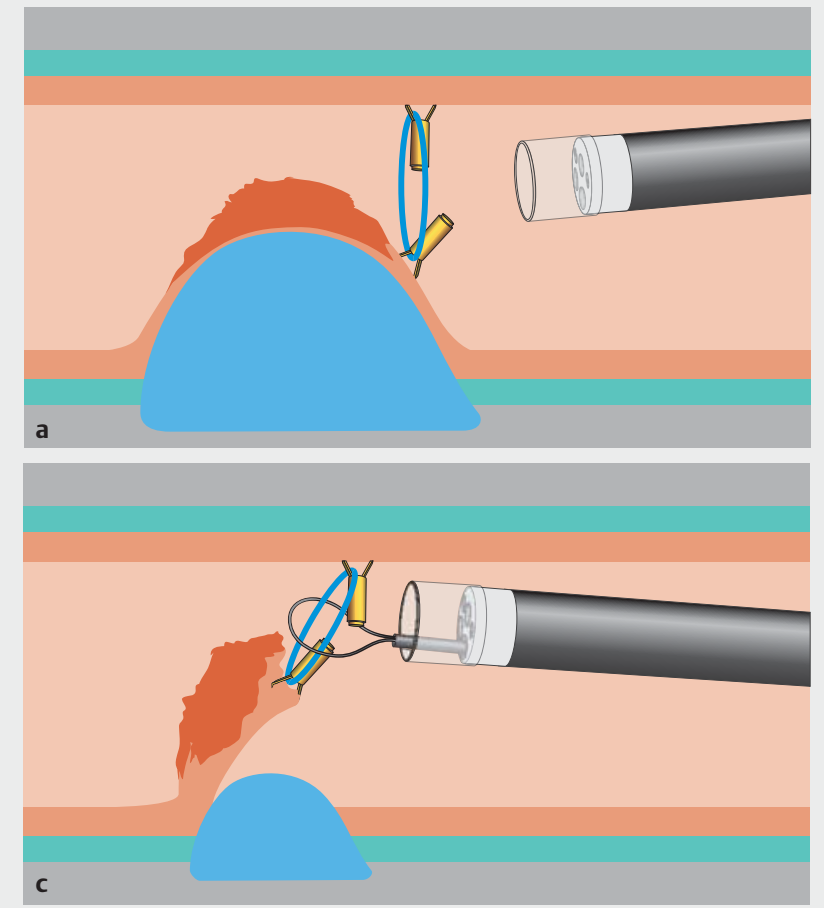
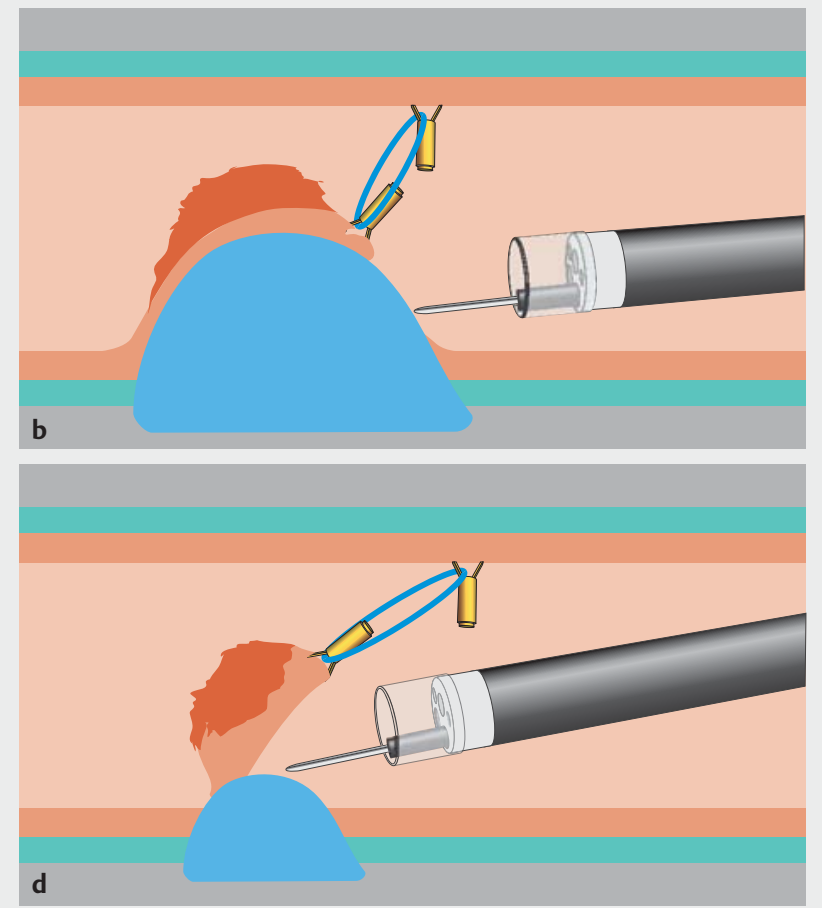

- Fig. 1 Schematic description of the strategy. a Endoscopic installation of the double-clip counter-traction at the anal side of the lesion after hemicircumferential mucosal incision. b Good exposure of the submucosal space as a result of the counter-traction. $\mathbf{c}$ Disappearance of the counter-traction effect after half of the lesion had been dissected. $\mathbf{d}$ Repositioning of the clip in a tent-like fashion to aid completion of the procedure.

The colon is the most technically challenging location for endoscopic submucosal dissection (ESD) of large, superficial, precancerous and cancerous lesions [1]. Appropriate exposure of the submucosal space can be very difficult, even when performed by experts, owing to the thinness of the submucosal space in this location and because the gravitational assistance is not constant. Moreover, the presence of colonic loops, bowel and respiratory movements, and position modifications resulting from insufflation increase the difficulty of performing ESD in this location.

Various strategies have been proposed to overcome these challenges, including pocket ESD [2] and the clip-with-line technique [3]. We recently reported the double-clip counter-traction method using a rubber band for large adenomas involving the appendix [4]. Here, we report a new strategy, which involves double-clip counter-traction using a rubber band and adjustment of the countertraction during the procedure.

As shown in > Fig. 1 and > Video 1, after hemicircumferential mucosal incision of a large sigmoid adenoma, the first clip was attached to the anal side of the lesion, grasping both the specimen and the rubber band. A second clip was then placed on the bowel wall in front of the lesion on the cecum side of the colonic wall to allow exposure of the submucosal space. Rapid and safe dissection was per- formed using this counter-traction method. However, the submucosal space narrowed progressively as the counter-traction effect subsided due to the specimen

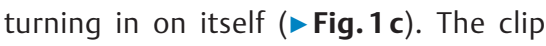
that was attached to the colonic wall was therefore removed using a $10-\mathrm{mm}$ polypectomy snare with gentle traction. A new clip, grasping the rubber band, was then placed on the colonic wall in front of the lesion on the anal side of the colonic wall, $5 \mathrm{~cm}$ distal to the specimen, to create traction in a tent-like fashion ( $\triangleright$ Fig.1d). Traction allowed rapid and safe completion of the dissection of this 7-cm adenoma with low grade dysplasia in less than 2 hours. 


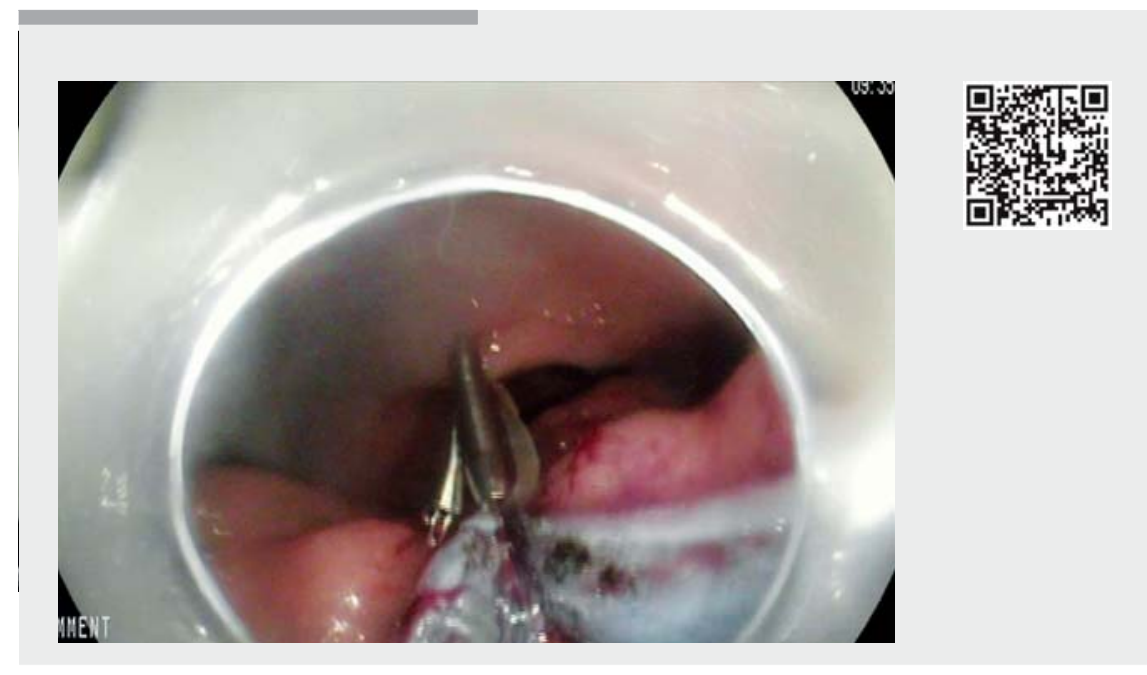

referral centers to evaluate this strategy in consecutive patients undergoing coIonic ESD.

Endoscopy_UCTN_Code_TTT_1AQ_2AD

Competing interests

None

$\checkmark$ Video 1 Endoscopic submucosal dissection (ESD) of a 7-cm, large, sigmoid adenoma with double-clip counter-traction using a rubber band. The sequence shows: difficult exposure of the submucosal space at the beginning of the dissection; placement of a rubber band with a clip to the anal side of the lesion; placement of a second clip to the opposite colonic wall grasping the rubber band; quick and safe ESD aided by the perfect exposure of the submucosal space; reduction in exposure due to the specimen turning in on itself; repositioning of the counter-traction in a tent-like fashion; good exposure aiding the completion of the procedure; extraction of the specimen; the resected specimen.

The double-clip strategy using a rubber band is an efficient and adaptive procedure that allows constant exposure of the submucosal layer, enabling safe and rapid ESD. Removal and repositioning of the clip during the procedure allow modification of the counter-traction to allow constant appropriate exposure of the submucosal space. A prospective study is currently ongoing in two French 
Jérémie Jacques ${ }^{1,2}$, Aurélie Charissoux ${ }^{3}$, Romain Legros ${ }^{1}$, Arnaud Tailleur ${ }^{1}$, Jérôme Rivory $^{4}$, Jérémie Albouis ${ }^{1}$, Mathieu Pioche ${ }^{4}$

1 Gastroentérologie et endoscopie digestive, CHU Dupuytren, Limoges, France

2 CNRS, XLIM, UMR 7252, Limoges, France

3 Anatomopathologie, CHU Dupuytren, Limoges, France

4 Unité d'endoscopie digestive, service de Gastroentérologie- pavillon H, Hôpital Edouard Herriot, Hospices Civils de Lyon, Lyon, France

\section{Corresponding author}

\section{Jérémie Jacques, MD}

service d'Hépato-gastro-entérologie, CHU Dupuytren 87042, Limoges, France

Fax: +33-5-55058733

jeremiejacques@gmail.com
[1] Fuccio L, Ponchon T. Colorectal endoscopic submucosal dissection (ESD). Best Pract Res Clin Gastroenterol 2017; 31: 473-480

[2] Sakamoto H, Hayashi Y, Miura Y et al. Pocket-creation method facilitates endoscopic submucosal dissection of colorectal laterally spreading tumors, non-granular type. Endosc Int Open 2017; 5: E123-129

[3] Yamasaki Y, Takeuchi Y, Uedo N et al. Traction-assisted colonic endoscopic submucosal dissection using clip and line: a feasibility study. Endosc Int Open 2016; 4: E51 - E55

[4] Utzeri E, Jacques ], Charissoux A et al. Traction strategy with clips and rubber band allows complete en bloc endoscopic submucosal dissection of laterally spreading tumors invading the appendix. Endoscopy 2017; 49: $820-822$

\section{Bibliography}

DOI https://doi.org/10.1055/s-0043-122596

Published online: 5.12.2017

Endoscopy 2018; 50: 179-181

(c) Georg Thieme Verlag KG

Stuttgart · New York

ISSN 0013-726X

\section{ENDOSCOPY E-VIDEOS}

https://eref.thieme.de/e-videos

口回 Endoscopy E-Videos is a free access online section, reporting 回舴: on interesting cases and new techniques in gastroenterological endoscopy. All papers include a high quality video and all contributions are freely accessible online.

This section has its own submission website at https://mc.manuscriptcentral.com/e-videos 